NBER WORKING PAPER SERIES

SOURCES OF OUTPUT AND PRICE VARIABILITY IN A

MACROECONOMETRIC MODEL

Ray C. Fair

Working Paper No. 2112

NATIONAL BUREAU OF ECONOMIC RESEARCH 1050 Massachusetts Avenue Cambridge, MA 02138

December 1986

The research reported here is part of the NBER's research program in Economic Fluctuations. Any opinions expressed are those of the author and not those of the National Bureau of Economic Research. 
NBER Working Paper \#2112

December 1986

\section{Sources of Dutput and Variability in a Macroeconometric Model}

\section{ABSTRACT}

There has been much recent discussion about the ultimate sources of macroeconomic variability. A number of authors attribute most of this variability to only a few sources, sometimes only one. Although there may be only a few important sources, this is far from obvious, since economies seem complicated. The purpose of this paper is to provide quantitative estimates of various sources of variability using my U.S. econometric model. Stochastic simulation is used to estimate how much the overall variances of real GNP and the GNP deflator are reduced when various shocks are surpressed in the model.

The results show two main things. The first is that the contribution of a given shock to the variance can vary considerably as the length ahead of the prediction varies. What is important for the one-quarter-ahead prediction may not be important for the eight-quarter-ahead prediction, and vice versa. The second is that the results imply that there are many important sources of variability for real GNP. It is not the case that one or two sources dominate. This is less true for the GNP deflator, however, where there are two very important sources, shocks to the price and wage equations and shocks to the price of imports, and one moderately important one, shocks to the government exogenous variables.

Ray C. Fair Cowles Foundation Box 2125, Yale Station New Haven, CT 06511 
December 1986

SOURCES OF OUTPUT AND PRICE VARIABILITY IN A MACROECONOMETRIC MODEL ${ }^{1}$

by

Ray C. Fair

\section{Introduction}

There has been much recent discussion about the ultimate sources of macroeconomic variability. Shiller (1987) surveys this work, where he points out that a number of authors attribute most of output or unemployment variability to only a few sources, sometimes only one. The sources vary from technology shocks for Kydland and Prescott (1982), to unanticipated changes in the money stock for Barro (1977), to "unusual structural shifts," such as changes in the demand for produced goods relative to services, for Lilien (1982), to oil price shocks for Hamiltion (1983), to changes in desired consumption for Hall (1986). (See Shiller (1987) for more references.) Although it may be that there are only a few important sources of macroeconomic variability, this is far from obvious. Economies seem complicated, and it may be that there are many important sources. The purpose of this paper is to estimate the quantitative importance of various sources of variability using a macroeconometric model.

Macroeconometric models provide an obvious vehicle for estimating the sources of variability of endogenous variables. There are two types of shocks that one needs to consider: shocks to the stochastic equations and shocks to the exogenous variables. Shocks to the stochastic equations are easy to handle. They are simply draws from the postulated distribution

${ }^{1}$ This paper grew out of discussions with Robert Shiller, to whom I am indebted for many helpful suggestions and comments. Some of the results in this paper are cited in Shiller (1987). The research described in this paper was financed by a grant from the National Science Foundation. 
(usually normal) of the structural error terms, the distribution upon which the estimation of the model is based. Shocks to the exogenous variables are less straightforward to handle. Since by definition exogenous variables are not modeled, it is not unambiguous what one means by an exogenous-variable shock. One possibility is to postulate, say, an autoregressive equation for each exogenous variable and take the error term from this equation as measuring the exogenous-variable shock. Another possibility is to postulate that exogenous-variable shocks are the errors that forecasting services make in their forecasts of the exogenous variables.

The sources of output and price variability are examined in this paper using my U.S. model (Fair (1984)). ${ }^{2}$ The procedure that was followed, which is discussed in detail in the next section, is briefly as follows. Autoregressive equations were estimated for 23 exogenous variables in the model. These variables make up all the important exogenous variables in the model (in my view). ${ }^{3}$ These equations were then added to the model. There are 30 structural stochastic equations in the model, and so the expanded model includes 53 stochastic equations. The $53 \times 53$ covariance matrix of the error terms was then estimated. In estimating this matrix the error terms in the structural equations were assumed to be uncorrelated with the error terms in the exogenous-variable equations, which means that the matrix was taken to be block diagonal (with a $30 \times 30$ block and a $23 \times 23$ block). This procedure is consistent with the assumption upon which the estimation

${ }^{2}$ Although the variability of only two endogenous variables, the level of output and the price level, is considered in this paper, the variability of any other endogenous variable in the model can be considered in the same way.

${ }^{3}$ The 23 exogenous variables are listed in the Appendix. 
of the model is based, namely that the exogenous variables are not correlated with the error terms in the structural equations.

Consider now real GNP, which is one of the endogenous variables in the model. Given the estimated covariance matrix of the error terms, one can estimate the variance of GNP by means of stochastic simulation. The variance of GNP can be estimated for the one-quarter-ahead prediction, the two-quarter-ahead prediction, and so on. Let $\tilde{\sigma}^{2}$ denote the estimated variance of real GNP for some given quarter and length ahead of the prediction. This estimated variance is based on draws of all 53 error terms in the model. Now consider fixing one of the error terms at its expected value (usually zero) and computing the variance of GNP again. In this case the stochastic simulation is based on draws of 52 error terms rather than 53. Let $\tilde{\sigma}^{2}(k)$ denote the estimated variance of real GNP based on fixing the error term in equation $k$ at its expected value.

The difference between $\tilde{\sigma}^{2}$ and $\tilde{\sigma}^{2}(k)$ is an estimate of how much the error term in equation $k$ contributes to the variance of GNP. One can thus examine the contribution of any of the 53 error terms to the variance of GNP. Also, $k$ need not refer to just one equation. One can fix the error terms in a subset $k$ of the equations at their expected values and draw from the remaining equations. In this way one can examine the contribution that various sectors make to the variance of GNP. In general, of course, the error terms across equations are correlated, and so it is not generally the case, for example, that fixing two error terms one at a time and then summing the two differences is the same as fixing the two error terms at the same time and computing the one difference. In most cases, however, one can get a fairly good idea of the contribution of each error term. The 
correlations of the error terms across equations are not so large as to make the present procedure a fruitless exercise. More will be said about this in Section III. ${ }^{4}$

There are two main features of the empirical results. The first is that the difference between $\tilde{\sigma}^{2}$ and $\tilde{\sigma}^{2}(k)$ for a given $k$ varies considerably across the forecast horizon. For some choices of $k$ the differences are large for the first few quarters ahead and then die out fairly quickly, while for other choices the differences start out small and build up considerably over the horizon. The second feature is that the results imply that there are many important sources of variability for real GNP. It is not the case that one or two sources dominate. This is less true for the GNP deflator, however, where there are two very important sources -- shocks to the price and wage equations and shocks to import prices - - one moderately important one -- shocks to the government exogenous variables -and the remaining sources of fairly minor importance.

It is important to realize what is and what is not being estimated in this paper. Consider an exogenous-variable shock. What is being estimated is the contribution of the error term in the exogenous-variable equation to the variance of GNP. This contribution is not the same as the multiplier effect of the exogenous variable on GNP. Two exogenous variables can have

\footnotetext{
${ }^{4}$ Robert Shiller has informed me that I have been scooped by Pigou. In the second edition of Industrial Fluctuations, Pigou (1929), after grouping sources of fluctuations into three basic categories, gave his estimate of how much the removal of each source would reduce the amplitude (i.e. the standard deviation) of industrial fluctuations. He thought that the removal. of "autonomous monetary causes" would reduce the amplitude by about half. Likewise, the removal of "psychological causes" would reduce the amplitude by about half. Removal of "real causes," such as harvest variations, would reduce the amplitude by about a quarter. See Shiller (1987) for more disucssion of this.
} 
the same multiplier effects and yet make quite different contributions to the variance of GNP. If one exogenous variable fits its autoregressive equation better than does another (in the sense that its equation has a smaller estimated variance), then, other things being equal, it will contribute less to the variance of GNP. It is, of course, possible to use measures of exogenous-variable shocks other than error terms from autoregressive equations, and in future work this may be of interest to do, but whatever measure is used, it is not likely to be the same as the size of the multiplier.

The results of this study do, of course, depend on the properties of my model. If the model is a reasonably good approximation of the macroeconomy, then some weight can be placed on the conclusions. If the model is a poor approximation, then the results cannot be trusted. I have done many tests with the model, some of which are discussed in Fair (1984), and it seems to me to be a reasonable approximation. In a recent test - F Fir (1986) -. I have compared the traditional expectations hypothesis used in the model with the rational expectations (RE) hypothesis. There is limited evidence for the RE hypothesis, and even when the RE hypothesis is given the benefit of the doubt in the estimation of the model, the properties of this version of the model are quite similar to the properties of the regular version of the model. This is not, however, the appropriate place to defend the model. Suffice it to say that the validity of the conclusions of this paper is based on the premise that the model is a good approximation of reality. 


\section{Methodology}

\section{The General Procedure}

Stochastic simulation can be used to estimate variances in nonlinear models. Write the model as

(1) $f_{i}\left(y_{t}, x_{t}, \alpha_{i}\right)=u_{i t}, i=1, \ldots, n, t=1, \ldots, T$,

where $y_{t}$ is an $n$-dimensional vector of endogenous variables, $x_{t}$ is a vector of predetermined variables, $\alpha_{i}$ is a vector of unknown coefficients, and $u_{i t}$ is an error term. The first m equations are assumed to be stochastic, with the remaining $u_{i t}(i=m+l, \ldots, n)$ identically zero for all $t$. It is assumed that $u_{t}=\left(u_{1 t}, \ldots, u_{m t}\right)$ is independently and identically distributed as multivariate normal $\mathrm{N}(0, \Sigma) .^{5}$ It is also assumed that consistent estimates of $\alpha_{i}$, denoted $\hat{\alpha}_{i}$, are available for all $i$. Given these estimates, consistent estimates of $u_{i t}$, denoted $\hat{u}_{i t}$, can be computed as $f_{i}\left(y_{t}, x_{t}, \hat{\alpha}_{i}\right)$. The covariance matrix $\Sigma$ can then be estimated as $(1 / \mathrm{T}) \hat{\mathrm{UU}} \hat{U}^{\prime}$, where $\hat{\mathrm{U}}$ is the $\mathrm{m}$ $\mathrm{x} T$ matrix of values of $\hat{u}_{i t}$.

Let $u_{t}^{*}$ denote a particular draw of the $m$ error terms for period $t$ from the $N(0, \hat{\Sigma})$ distribution. Given $u_{t}^{*}$ and given $\hat{\alpha}_{i}$ for all $i$, one can solve the model for period $t$. This is merely a deterministic simulation for the given values of the error terms and coefficients. Call this simulation a "trial." Another trial can be made by drawing a new set of values of $u_{t}^{*}$ and solving again. This can be done as many times as desired. From each trial one obtains a prediction of each endogenous variable. Let $\mathrm{y}_{i t}^{j}$ denote the value on the $j$ th trial of variable $i$ for period $t$. For $J$ trials, the stochastic

${ }^{5}$ Although the normality assumption is used throughout this paper, other assumptions could be used. This would simply change the way the error terms are drawn. 
simulation estimate of the expected value of variable $i$ for period $t$, denoted $\tilde{\mu}_{i t}$, is

(2) $\tilde{\mu}_{i t}=(1 / J) \sum_{j=1}^{J} y_{i t}^{j}$.

The stochastic simulation estimate of the variance of variable $i$ for period $t$, denoted $\tilde{\sigma}_{i t}^{2}$, is

(3) $\tilde{\sigma}_{i t}^{2}=(1 / J) \underset{j=1}{\mathrm{~J}}\left(y_{i t}^{\mathrm{j}}-\tilde{\mu}_{i t}\right)^{2}$,

where $\tilde{\mu}_{i t}$ is determined in (2).

In many applications one is interested in predicted values more than one period ahead, i.e. in predicted values from dynamic simulations. The above discussion is easily modified to incorporate this case. One simply draws values for $u_{t}$ for each period of the simulation. Each trial is one dynamic simulation over the period of interest. If, for example, the period is eight quarters, one obtains eight predicted values of variable $i$ from one trial. Given then $J$ values of the p-quarter-ahead forecast of variable $i$, one can compute the mean and variance of this forecast using (2) and (3).

It is also possible to draw coefficients for the trials. Given an estimate of the distribution of the coefficient estimates, which one has from the estimation of the model, coefficient values can be drawn. In this case each trial consists of draws of both error terms and coefficients. This paper, however, is not concerned with uncertainty from the coefficient estimates, and only draws of the error terms are made. The coefficients are the same from trial to trial.

The next issue to consider is the treatment of the exogenous variables. If the exogenous-variable values are the same from trial to trial, then the 
estimated variances are conditional on fixed values of the exogenous variables. It is also possible, however, to take into account exogenousvariable uncertainty in computing the estimated variances. As noted in the Introduction, there are a number of ways in which this can be done. One straightforward way, which is done here, is to add equations explaining the exogenous variables to the model. For purposes of this paper, an eighth order autoregressive equation (with a constant term and time trend included) was estimated for each exogenous variable of interest and these equations were added to the model. Stochastic simulation can then be done for this expanded version of the model. By drawing error terms from the equations explaining the exogenous variables, exogenous-variable uncertainty is taken into account.

Assume that there are $q$ exogenous-variable equations added to the model. This means that the covariance matrix $\Sigma$ is now $(m+q) x(m+q)$. In estimating this matrix one may want to take $\Sigma$ to be block diagonal, where the first block is the original $\mathrm{m} \mathrm{m}$ matrix and the second block is the $q \times q$ estimated covariance matrix of the error terms in the exogenousvariable equations. As noted in the Introduction, this procedure is consistent with the assumption upon which the estimation of the model is based.

The notation $\tilde{\sigma}_{i t}^{2}$ will be used to denote the estimated variance based on draws of all $m+q$ error terms. The notation $\tilde{\sigma}_{i t}^{2}(k)$ will be used to denote the estimated variance when the error terms in subset $k$ of the equations are fixed at their expected values, where subset $k$ can simply be one equation. Let $\tilde{\delta}_{i t}(k)$ be the difference between the two estimated variances:

(4) $\delta_{i t}(k)=\tilde{\sigma}_{i t}^{2}-\tilde{\sigma}_{i t}^{2}(k)$. 
In the next section, values of $\tilde{\delta}_{i t}(k)$ are computed for the one-through eight-quarter-ahead predictions of real GNP and the GNP deflator for a number of different choices of $k$.

Because of the correlation of the error terms across equations, it can turn out that $\tilde{\delta}_{i t}(k)$ is negative for some choices of $k$. Also, as noted in the Introduction, it is not in general the case that $\delta_{i t}(k)$ for, say, $k$ equal to the first and second equations is the same as $\delta_{i t}(k)$ for $k$ equal to the first equation plus $\delta_{i t}(k)$ for $k$ equal to the second equation.

\section{Computational Issues}

For a number of reasons the stochastic-simulation estimates of the variances are not exact. First, they are based on the use of estimated coefficients rather than the true values. Second, they are based on the use of an estimated covariance matrix of the error terms rather than the actual matrix. Third, they are based on a finite number of trials. Ignoring the first two reasons, it is possible to estimate the precision of the stochastic-simulation estimates for a given number of trials. In other words, it is possible to estimate the variances of $\tilde{\sigma}_{i t}^{2}$ and $\tilde{\sigma}_{i t}^{2}(k)$. What is of more concern here, however, is the variance of $\delta_{i t}(k)$, and this can also be estimated. The estimation of these variances is explained in the Appendix .

Stochastic-simulation error turned out to be a bigger problem than I originally thought it would be. One thousand trials was enough to make the variances of $\tilde{\sigma}_{i t}^{2}$ and $\tilde{\sigma}_{i t}^{2}(k)$ acceptably small, but without any tricks, it was not enough to make the variance of $\tilde{\delta}_{i t}(k)$ anywhere close to being acceptably small. Fortunately, there is an easy trick available. The variance of 
$\tilde{\delta}_{i t}(k)$ is equal to the variance of $\tilde{\sigma}_{i t}^{2}$ plus the variance of $\tilde{\sigma}_{i t}^{2}(k)$ minus twice the covariance. The trick is to make the covariance high, which can be done by using the same draws of the error terms for the computation of both $\tilde{\sigma}_{i t}^{2}$ and $\tilde{\sigma}_{i t}^{2}(k)$. Any one equation of the model, for example, requires 8000 draws of its error term for 1000 trials for a forecast horizon of 8 quarters. If these same 8000 number are used to compute both $\tilde{\sigma}_{i t}^{2}$ and $\tilde{\sigma}_{i t}^{2}(k)$, the covariance between them will be increased. When this trick is used, as shown in the Appendix, 1000 trials leads to variances of $\delta_{i t}(k)$ that are acceptably small.

\section{The Results}

My model is described in detail in Fair (1984), and it will not be discussed here. The model has been estimated through 1986 II for this study. The beginning quarter is $1954 \mathrm{I}$, and so there are 130 sample observations. There are 30 structural stochastic equations and 98 identities. There are 23 autoregressive equations for the exogenous variables. The structural equations have been estimated by two stage least squares and the autoregressive equations by ordinary least squares. The eight-quarter prediction period for the simulations was 1981 III - 1983 II.

The stochastic-simulation work was done in two steps. For the first step 54 stochastic simulations were performed of 100 trials each. For the first simulation none of the equations' error terms was fixed, and for each of the remaining 53 simulations one equation's error term per simulation was fixed. The variance of $\xi_{i t}(k)$ depends of the size of $\delta_{i t}(k)$, and for choices of $k$ where the size is quite small, sufficient accuracy can be obtained with 100 trials. The first step thus allowed one to determine 
those equations whose error terms contribute very little to the overall variance. There were 11 such equations. ${ }^{6}$ This left 43 equations to consider further.

For the second step 32 simulations were run of 1000 trials each. The first simulation was again where none of the equations' error terms was fixed. Each of the other 31 simulations consisted of fixing one or more of the remaining 43 equations' error terms. ${ }^{7}$ The results from these simulations will now be presented.

The results for real GNP will be discussed first. For ease of interpretation, the differences will be presented as a percent of the overall variance in percentage points. In other words, the values presented in what follows are $100\left[\tilde{\delta}_{i t}(k) / \tilde{\sigma}_{i t}^{2}\right]$.

The first stochastic simulation that was performed after the base simulation (where all 53 errors were drawn) was one in which the error terms in the 23 exogenous-variable equations were fixed at their expected values. This allows one to see how much of the variance of real GNP is due to the combined exogenous-variable shocks. The results are:

$$
\begin{array}{lllllllll}
\multicolumn{8}{c}{\text { Quarters Ahead }} \\
& 2 & 3 & 4 & 5 & 6 & 7 & 8
\end{array}
$$
All exogenous equations
$25.5 \quad 28.3 \quad 31.8 \quad 34.7$
$37.7 \quad 40.0 \quad 43.0 \quad 43.6$

6

The variables explained by the 11 equations are 1) labor force participation of men 25-54,2) labor force participation of women 25-54,3) labor force participation of all others 16 and over, 4) number of people holding two jobs, 5) dividend payments of the firm sector, 6) interest payments of the firm sector, 7) inventory valuation adjustment, 8) capital consumption of the firm sector, 9) member bank borrowing from the Federal Reserve, 10) unemployment insurance benefits, 11) interest payments of the
Federal government.

7 Each (eight quarter) simulation of 1000 trials takes about 5 hours of CPU time on a VAX 730. The 32 simulations thus took about a week of CPU time. Counting initial experimentation time, various false starts, and some errors, the computer work for this paper took about a month of CPU time. 
For the one-quarter-ahead prediction 25.5 percent of the variance of real GNP is due to the exogenous-variable shocks. This figure rises to 43.6 percent for the eight-quarter-ahead prediction. ${ }^{8}$ The exogenous-variable shocks thus contribute a considerable amount to the variance.

The next stochastic simulations were designed to examine the contribution of household-sector shocks to the overall variance. The main equations of the household sector in the model are three consumption equations and a housing investment equation. ${ }^{9}$ The error terms in these equations were fixed one at a time and then altogether. The results are:

\begin{tabular}{lcccccccc} 
& & \multicolumn{7}{c}{ Quarters Ahead } \\
& 1 & 2 & 3 & 4 & 5 & 6 & 7 & 8 \\
Consumption of services & 9.0 & 9.3 & 9.1 & 9.2 & 9.5 & 9.8 & 8.8 & 8.7 \\
Consumption of nondurables & 5.2 & 7.0 & 6.3 & 4.6 & 5.7 & 4.2 & 3.2 & 2.3 \\
Consumption of durables & 18.8 & 15.9 & 12.9 & 10.1 & 8.5 & 6.3 & 6.8 & 5.0 \\
Housing investment & 11.1 & 12.2 & 9.4 & 15.4 & 14.6 & 12.9 & 10.8 & 8.2 \\
ALL FOUR TOGETHER & 33.7 & 32.8 & 32.1 & 29.3 & 28.7 & 24.2 & 21.9 & 17.7
\end{tabular}

${ }^{8}$ These figures are an underestimate of the contribution of all the exogenous variables in the model to the variance of GNP because equations for only 23 exogenous variables have been estimated. There are 88 exogenous variables in the model for which equations could be estimated. The 65 variables for which equations were not estimated are, however, of fairly minor importance in the model, many of them having to do with the linking of the National Income Accounts with the Flow of Funds Accounts, and it is unlikely that they would contribute much to the variance. It would have taken much more computer time to deal with 88 exogenous-variable equations rather than 23 .

Note also that what is referred to here as the overall variance of GNP (or the GNP deflator below) is the variance taking into account only the 23 exogenous-variable shocks, not 88 shocks.

${ }^{9}$ There are also four labor supply equations of the household sector, three labor force participation equations and an equation explaining the number of people holding two jobs. The error terms in these equations contributed a very small amount to the variance of GNP, and the results for these equations are not worth reporting. 
The shocks to the equations for the household sector contribute a considerable amount to the variance of GNP, from 33.7 percent for the onequarter ahead prediction to 17.7 percent for the eight-quarter-ahead. Shocks to the consumption of durables and housing investment equations contribute the most in the beginning. Shocks to the consumption of services equation have a fairly stead influence across the horizon. In terms of the effects of the correlation of the error terms across equations, the sum of the four individual percents for a given quarter ahead is about a third bigger than the percent for all four taken together. This is not a trivial difference, but it seems unlikely to affect the basic conclusions that are drawn from the individual results.

The next simulations examined the contribution of firm-sector shocks. Four simulations were run -- one fixing the error term in the inventory investment equation; one fixing the error term in the plant and equipment investment equation; one fixing the error terms in the equations for the demand for workers, the demand for hours per worker, and the demand for overtime hours; and one fixing the error terms in all five equations. (The firm sector also sets prices and wages, but these equations are examined separately below.) The results are:

\begin{tabular}{|c|c|c|c|c|c|c|c|c|}
\hline & \multicolumn{8}{|c|}{ Quarters Ahead } \\
\hline & 1 & 2 & 3 & 4 & 5 & 6 & 7 & 8 \\
\hline Inventory investment & 28.7 & 17.3 & 9.8 & 6.9 & 6.7 & 2.3 & 5.5 & 4.4 \\
\hline$P \& E$ investment & 5.8 & 4.3 & 4.0 & 2.6 & 2.5 & 2.8 & 2.9 & 2.2 \\
\hline $\begin{array}{l}\text { Demand for 1) workers, } \\
\text { 2) hours per worker, } \\
\text { 3) overtime hours }\end{array}$ & -1.1 & -1.4 & -0.9 & -0.8 & -0.8 & -0.8 & -0.8 & -0.4 \\
\hline ALL FIVE TOGETHER & 33.4 & 20.7 & 13.1 & 9.0 & 8.1 & 4.3 & 7.6 & 5.6 \\
\hline
\end{tabular}


Shocks to the inventory investment equations contribute a lot in the beginning, but their contribution dies out fairly quickly. The contribution of shocks to the plant and equipment investment equation is at best only moderate. The figures for the demand for workers, hours, and overtime hours are negative, which means that the variance of GNP is larger when the error terms in these equations are fixed. In other words, the correlation of the error terms in the model is such that the error terms in these equations contribute negatively to the overall variance. The figures are, however, quite small, and so there is little contribution of any sort from this source. Note finally that the sum of the three individual percents for a given quarter ahead is quite close to the percent for all the equations taken together.

There is one price equation and one wage equation in the model, and for the next simulation the error terms in these two equations were fixed. The results are:

\begin{tabular}{cccccccccc} 
& \multicolumn{8}{c}{ Quarters Ahead } \\
& 1 & 2 & 3 & 4 & 5 & 6 & 7 & 8 \\
Price and wage equations & 0.2 & 3.3 & 4.8 & 5.7 & 7.1 & 8.0 & 8.3 & 10.5
\end{tabular}
The price and wage shocks have little effect in the beginning, but the contribution builds up to 10.5 percent by eight quarters.

The financial part of the model was examined next. Four simulations were run. 1) The error terms in the three money demand equations were fixed. 2) The error term in the interest rate reaction function of the Federal Reserve, which determines the three-month Treasury bill rate, was fixed. 3) The error terms in the two term structure of interest rate 
equations, which determine the corporate bond rate and the mortgage rate respectively, were fixed. 4) The error term in the stock price equation was fixed. The results are:

\begin{tabular}{lcccccccc} 
& \multicolumn{7}{c}{ Quarters Ahead } \\
& 1 & 2 & 3 & 4 & 5 & 6 & 7 & 8 \\
Three money demand eqs. & -0.0 & -0.2 & -1.1 & -1.9 & -1.4 & -1.9 & -2.1 & -1.5 \\
$\begin{array}{l}\text { Interest rate reaction } \\
\text { function }\end{array}$ & -0.0 & 0.8 & 2.0 & 2.9 & 2.9 & 2.8 & 2.8 & 3.1 \\
Two term structure eqs. & 1.4 & 2.1 & 2.2 & 2.3 & 2.0 & 2.7 & 3.5 & 3.9 \\
Stock price equation & 0.0 & 1.2 & 2.6 & 4.0 & 5.0 & 5.9 & 5.7 & 6.1
\end{tabular}

The contributions are fairly small except for the stock price equation after about four quarters. It is interesting to note that the shocks to the Federal Reserve's interest rate reaction function do not contribute very much. It is important to realize, however, that this does not mean that the Fed itself is ineffective and that monetary policy is not important in the model. (Monetary policy is in fact quite important in the model - see, for example, the results in Chapter 9 in Fair (1984).) It simply means that the effects of the shocks to the reaction function are fairly small.

When the interest rate reaction function is included in the model, as it is for all the simulations in this study, monetary policy is endogenous. This means that the demand for money equations affect the short term interest rate only because the lagged growth of the money stock is an explanatory variable in the interest rate reaction function. It is not the case, for example, that the money supply is fixed and that shocks to the money demand equations directly affect the interest rate. It is thus not surprising that the shocks to the money demand equations contribute very 
little to the variance of GNP.

There is a demand for imports equation in the model, and the error term in this equation was fixed next:

\begin{tabular}{crrrrrrrr} 
& \multicolumn{9}{c}{ Quarters Ahead } \\
& 1 & 2 & 3 & 4 & 5 & 6 & 7 & 8 \\
Import equation & -14.7 & -9.6 & -4.3 & -1.2 & -1.2 & 3.0 & 5.1 & 6.7
\end{tabular}

The correlations of the error term in the import equation with the error terms in the other structural equations are such as to lead to a fairly large negative contribution in the first few quarters. In other words, shocks to the import equation are initially somewhat stabilizing.

This completes the simulations for the structural stochastic equations. The shocks to the exogenous-variable equations will now be discussed. Nine stochastic simulations were performed regarding the exogenous variables in the government sector. The results are ( $F$ stands for federal government and $S$ stands for state and local government):

\begin{tabular}{|c|c|c|c|c|c|c|c|c|}
\hline & & & & rters & Ahead & & & \\
\hline & 1 & 2 & 3 & 4 & 5 & 6 & 7 & 8 \\
\hline F purchases of goods & 7.9 & 6.1 & 6.2 & 5.5 & 6.0 & 6.3 & 7.0 & 6.9 \\
\hline Five $F$ tax rates & -0.1 & -0.3 & -0.0 & 0.9 & 2.2 & 3.5 & 4.0 & 3.6 \\
\hline $\begin{array}{l}\text { Three } F \text { demand for workers } \\
\text { and hours variables }\end{array}$ & 1.1 & 1.4 & 1.8 & 1.7 & 1.5 & 1.4 & 1.5 & 1.7 \\
\hline $\begin{array}{l}\text { F transfer payments to } \\
\text { households }\end{array}$ & -1.1 & -2.0 & -1.2 & -1.5 & -2.4 & -2.3 & -2.2 & -2.2 \\
\hline S purchases of goods & 2.3 & 2.6 & 2.9 & 2.9 & 3.0 & 3.2 & 3.4 & 4.0 \\
\hline Five $S$ tax rates & 0.1 & 0.3 & 0.5 & 0.6 & 1.2 & 1.7 & 2.6 & 3.0 \\
\hline $\begin{array}{l}\text { One } S \text { demand for workers } \\
\text { variable }\end{array}$ & 0.4 & 0.7 & 0.6 & 0.4 & 0.4 & 0.7 & 0.8 & 1.0 \\
\hline
\end{tabular}


$S$ transfer payments to

households

$$
\begin{array}{llllllll}
0.0 & 0.1 & 0.4 & 0.9 & 0.8 & 0.7 & 0.7 & 0.6
\end{array}
$$

$\begin{array}{llllllllll}\text { ALL VARIABLES TOGETHER } & 10.2 & 8.5 & 10.5 & 11.4 & 13.8 & 16.7 & 19.5 & 20.5\end{array}$

These results are fairly self explanatory. The shocks to the exogenous variables in the government sector (federal plus state and local) contribute 20.5 percent of the variance of GNP eight quarters out. There are 18 exogenous-variable equations involved for the above results: 10 tax rate equations, 2 goods purchases equations, 4 labor purchase equations, and 2 transfer payments equations. The five tax rates for each government are 1) a personal income tax parameter, 2) the corporate tax rate, 3) the indirect business tax rate, 4) the employer social security tax rate, and 5) the employee social security tax rate. The four labor purchase variables are federal civilian employment, federal military employment, federal hours paid per civilian worker, and state and local employment.

The two key exogenous variables with respect to the foreign sector are the real value of exports and the price of imports. The results of the simulations with the error term in each of these equations fixed are:

\begin{tabular}{lrrrrrrrrr} 
& & \multicolumn{8}{c}{ Quarters Ahead } \\
& 1 & 2 & 3 & 4 & 5 & 6 & 7 & 8 \\
Exports & 13.9 & 15.0 & 16.0 & 19.7 & 21.6 & 21.0 & 20.9 & 18.6 \\
Price of imports & -0.4 & -0.7 & -1.1 & -1.8 & -2.7 & -3.1 & -3.4 & -3.4
\end{tabular}

Export shocks are obviously a large source of the variance of GNP. These percents are, for example, much larger than the above percents for federal purchases of goods, even though exports and federal purchases of goods have similar multiplier effects. Part of this difference may be due to different 
correlations of the error terms across the exogenous-variable equations for exports than for government purchases of goods, but most of it is probably due to the fact that the export equation has a larger estimated variance than does the government purchases of goods equation. Shocks to the price of imports equation make a negative but fairly small (in absolute value) contribution to the variance of GNP.

There are three population variables in the model: the population of men 25-54, women 25-54, and all others 16 and over. When the error terms in the three equations explaining these variables are fixed, the results are:

\begin{tabular}{cccccccccc} 
& \multicolumn{1}{c}{ Quarters Ahead } \\
& 1 & 2 & 3 & 4 & 5 & 6 & 7 & 8 \\
Three population variables & 0.4 & 0.3 & 0.9 & 0.8 & 0.6 & 0.4 & 0.2 & 0.4
\end{tabular}

It is obvious that shocks to population do not amount to very much.

This completes the results for real GNP. The results show that the contributions from the various sources vary across the length ahead of the prediction. They also show for any given length that no one or two sources dominate. For the eight-quarter-ahead prediction, the contributions in order of importance are 20.5 percent for the government sector, 18.6 percent for exports, 17.7 percent for the household sector, 10.5 percent for prices and wages, 6.7 percent for imports, 6.1 percent for stock prices, 5.6 percent for the firm sector, 3.9 percent for the term structure equations, 3.1 percent for the interest rate reaction function, and 0.4 percent for population. The negative contributors are -3.4 percent for the price of imports and -1.5 percent for the money demand equations.

The results for the GNP deflator are easier to present because fewer shocks matter. Consider first the simulation in which the error terms in 
The contribution is at first positive and then turns negative, although even here the effects are not very large.

The results when the error terms in all the government exogenousvariable equations are fixed are:

\begin{tabular}{cccccccccc} 
& \multicolumn{1}{c}{ Quarters Ahead } \\
& 1 & 2 & 3 & 4 & 5 & 6 & 7 & 8 \\
ALL GOVERNMENT VARIABLES & 8.1 & 10.4 & 11.1 & 11.4 & 11.6 & 11.1 & 9.2 & 8.7
\end{tabular}

The shocks to the government variables contribute about 10 percent to the variance of the GNP deflator. The results for exports and the price of imports are:

\begin{tabular}{lccccccccc} 
& \multicolumn{8}{c}{ Quarters Ahead } \\
& 1 & 2 & 3 & 4 & 5 & 6 & 7 & 8 \\
Exports & -0.7 & -0.6 & -0.1 & 0.8 & 1.4 & 2.3 & 3.2 & 3.6 \\
Price of imports & 0.8 & 4.8 & 13.1 & 21.2 & 31.3 & 41.0 & 50.3 & 58.3
\end{tabular}

Shocks to exports do not amount to very much, but shocks to the price of imports obviously do. By eight quarters out shocks to the price of imports account for 58.3 percent of the variance of the GNP deflator.

It is clear from the results for the GNP deflator that there are two main sources of variability, shocks to the price and wage equations and shocks to the price of imports. Most of the variability for the first few quarters is due to shocks to the price and wage equations, but after six quarters shocks to the price of imports become more important. Eight quarters out, shocks to exports and the government exogenous variables contribute a little over 10 percent to the variance. The contributions from the other shocks, which are not reported here, were all minor. 


\section{Conclusion}

The methodology of this study allows one to get a good idea of the quantitative contribution of various shocks to the variance of endogenous variables like real GNP and the GNP deflator. For the variance of the GNP deflator there are two main sources of variability: shocks to the price and wage equations and shocks to the price of imports. Of the other sources, shocks to the government exogenous variables contribute about 10 percent to the variance of the GNP deflator. For the variance of real GNP there are many important shocks; it is clearly not the case that one or two shocks dominate. In short, there are no simple stories to be told about the sources of output variability, at least not within the context of a macroeconometric model like mine. 


\section{APPENDIX}

The calculation of the simulation-error variances is discussed in this appendix, and some examples are presented. In the text $y_{i t}^{j}$ denotes the predicted value of variable $i$ for period $t$ on the $j$ th trial. For purposes of this appendix, the it subscript will be dropped. The following discussion always pertains to variable $i$ for period $t$. The stochasticsimulation estimate of the expected value of variable $i$ for period $t$ is given by equation (2) in the text, which is repeated here in the current notation:

(A1) $\tilde{\mu}=(1 / \mathrm{J}) \underset{j=1}{\mathrm{~J}} \mathrm{y}^{\mathrm{j}}$.

Let

(A2) $\sigma^{2 j}=\left(y^{j}-\tilde{\mu}\right)^{2}$.

The stochastic-simulation estimate of the variance of variable $i$ for period $t$, which is given by equation ( 3 ) in the text, is then:

(A3) $\tilde{\sigma}^{2}=(1 / \mathrm{J}) \underset{\mathrm{j}=1}{\mathrm{~J}} \sigma^{2 j}$.

An estimate of the variance of $\tilde{\sigma}^{2}$, denoted $\operatorname{var}\left(\tilde{\sigma}^{2}\right)$, is

(A4) $\operatorname{var}\left(\tilde{\sigma}^{2}\right)=(1 / \mathrm{J})^{2} \sum_{j=1}^{\mathrm{J}}\left(\sigma^{2 j}-\tilde{\sigma}^{2}\right)^{2}$.

(Note also that an estimate of the variance of $\tilde{\mu}$ is $\tilde{\sigma}^{2} / \mathrm{J}$, although this estimate is not needed for the present analysis.)

As in the text, the notation (k) will be used to denote a stochastic simulation where the error terms in subset $k$ of the equations are fixed at their expected values. Let 
(A5) $\mathrm{d}^{\mathrm{j}}(\mathrm{k})=\sigma^{2 \mathrm{j}}-\sigma^{2 \mathrm{j}}(\mathrm{k})$.

The estimated mean of $\mathrm{d}^{j}(k)$, denoted $\tilde{\delta}(k)$, is

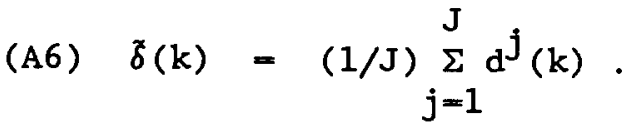

Equation (A6) is the same as equation (4) in the text. $\delta(k)$ is the difference between the two estimated variances. The estimated variance of $\delta(k)$, denoted $\operatorname{var}[\delta(k)]$, is then

(A7) $\operatorname{var}[\delta(k)]=(1 / J)^{2} \underset{j=1}{J}\left[d^{j}(k)-\delta(k)\right]^{2}$

Given values of $y^{j}$ and $y^{j}(k), j=1, \ldots J$, all the above values can be computed.

The following results give one an idea of the precision of the estimates based on 1000 trials. These are the results used in the paper for real GNP. The units are in billions of 1982 dollars.

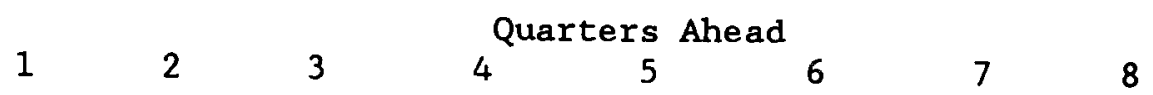
$\begin{array}{lllllllll}\tilde{\sigma}^{2} & & & & & & \\ \left(\operatorname{var}\left(\tilde{\sigma}^{2}\right)\right\}^{1 / 2} & 400.2 & 807.1 & 1250.7 & 1689.3 & 2212.5 & 2616.1 & 3207.4 & 3512.3 \\ & (17.5) & (32.8) & (52.6) & (69.2) & (93.2) & (109.8) & (135.4) & (153.5)\end{array}$

A11 exog. eqs.

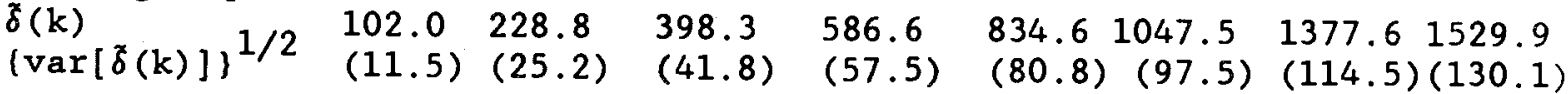

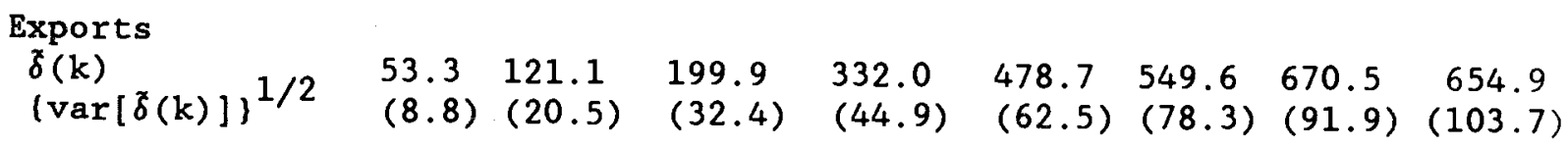

Stock price eq. $\begin{array}{lcccccccc}\delta(k) & 0.005 & 9.3 & 32.9 & 66.8 & 110.4 & 153.7 & 184.4 & 214.1 \\ (\operatorname{var}[\delta(k)])^{1 / 2} & (0.006) & (2.1) & (5.9) & (10.6) & (16.9) & (23.7) & (31.4) & (37.7)\end{array}$ 
The first row presents the estimates of the variance of real GNP, and the second row presents the estimated standard errors of the variance estimates. The variance estimates are fairly precise, with estimated standard errors less than 5 percent of the variance estimates. The next two rows pertain to the stochastic simulation in which the error terms in all the exogenousvariable equations were fixed. The values of the difference are presented in the first of the two rows, and the estimated standard errors of the difference values are presented in the second of the two rows. The standard errors are generally less than 10 percent of the difference values, and so the precision is reasonably good. The same two rows are presented for the simulation in which the error term in the export equation was fixed and for the simulation in which the error term in the stock price equation was fixed. In these two cases the precision is somewhat less; the standard errors are around 15 percent of the difference values.

For all the stochastic simulations the standard errors of the difference values seemed small enough to allow meaningful comparisons to be made, although they are still fairly far from zero. Remember that these estimates are based on the trick of using the same draws for both simulations. Without this trick, the standard errors are much too large for anything meaningful to be done with the difference values.

Finally, the 23 exogenous variables for which autoregressive equations were estimated are the following:

1. Federal purchases of goods.

2. Federal personal income tax parameter.

3. Federa1 corporate tax rate.

4. Federal indirect business tax rate.

5. Federal employer social security tax rate.

6. Federal employee social security tax rate.

7. Federal transfer payments to households. 
8. Federal civilian employment.

9. Federal military employment.

10. Federal hours paid per worker.

11. State and local purchases of goods.

12. State and local personal income tax parameter.

13. State and local corporate tax rate.

14. State and local indirect business tax rate.

15. State and local employer social security tax rate.

17. State and local transfer payments to households.

18. State and local employment.

19. Exports.

20. Price of imports.

21. Population of men 25-54.

22. Population of women 25-54.

23. Population of all others 16 and over. 


\section{REFERENCES}

Barro, Robert J., "Unanticipated Money Growth and Unemployment in the United States," American Economic Review, 67 (March 1977), 101-115.

Fair, Ray C., Specification, Estimation, and Analysis of Macroeconometric Models, Cambridge: Harvard University Press, 1984.

Fair, Ray C., "The Use of Expected Future Variables in Macroeconometric Models, mimeo, 1986.

Hal1, Robert E., "The Role of Consumption in Economic Fluctuations," in Robert J. Gordon, ed., The American Business Cycle: Continuity and Change, Chicago: NBER and University of Chicago Press, 1986.

Hamilton, James D., "Oil and the Macroeconomy since World War II," Journal of Political Economy, 91 (April 1983), 228-248.

Kydland, Finn E., and Edward C. Prescott, "Time to Build and Aggregate Fluctuations," Econometrica 50 (1982), 1345-1370.

Lilien, David M., "Sectoral Shifts and Cyclical Unemployment," Journal of Political Economy, 90 (August 1982), 777-793.

Pigou, Arthur C., Industrial Fluctuations, 2nd. ed., London: Macmillan, 1929.

Shiller, Robert J., "Ultimate Sources of Aggregate Variability, "American Economic Review, forthcoming May 1987. 